\title{
Corrigendum
}

\section{Corrigendum to "Efficacy and Safety of Butorphanol Use in Patient-Controlled Analgesia: A Meta-Analysis"}

\author{
Zhihua Zhu and Wenyu Zhang \\ Department of Anesthesiology, China-Japan Union Hospital of Jilin University, Changchun, Jilin, China \\ Correspondence should be addressed to Wenyu Zhang; wyzhang@jlu.edu.cn \\ Received 24 September 2021; Accepted 24 September 2021; Published 23 October 2021 \\ Copyright ( $\odot 2021$ Zhihua Zhu and Wenyu Zhang. This is an open access article distributed under the Creative Commons \\ Attribution License, which permits unrestricted use, distribution, and reproduction in any medium, provided the original work is \\ properly cited.
}

In the article titled "Efficacy and Safety of Butorphanol Use in Patient-Controlled Analgesia: A Meta-Analysis" [1], the funding statement was omitted by mistake and is as follows.

\section{Acknowledgments}

The study was supported by the Natural Science Foundation of Jilin Province Joint Fund of Bethune Medical Specialty (no. 20200201618JC).

\section{References}

[1] Z. Zhu and W. Zhang, "Efficacy and safety of butorphanol use in patient-controlled analgesia: a meta-analysis," EvidenceBased Complementary and Alternative Medicine, vol. 2021, Article ID 5530441, 9 pages, 2021. 